Int. J. Electrochem. Sci., 15 (2020) $666-676$

International Journal of

ELECTROCHEMICAL

SCIENCE

www.electrochemsci.org

\title{
Mechanistic Interpretation for Xanthate Adsorption onto Galena through Electrochemical Impedance Spectrum Fitting by a Differential Evolution Algorithm
}

\author{
E.D. Moreno-Medrano ${ }^{1 *}$, Valentín Osuna-Enciso ${ }^{1}$, N. Casillas $^{2}$, M. A. Pedroza-Toscano ${ }^{3}$, \\ A. Gutierrez-Becerra ${ }^{1}$, E.R. Larios-Durán ${ }^{4}$ \\ ${ }^{1}$ Engineering and Basic Sciences Department, University of Guadalajara, CUTonalá, 48525, México; \\ edgar.mmedrano@academicos.udg.mx, valenteos@hotmail.com, algubec@gmail.com \\ ${ }^{2}$ Chemistry Department, University of Guadalajara, CUCEI. Gdl., 44430, México; \\ ncasa@ hotmail.com \\ ${ }^{3}$ University Center UTEG, Gdl. 44430, México; mpedroza@uteg.edu.mx \\ ${ }^{4}$ Chemical Engineering Department, University of Guadalajara, CUCEI. Gdl., 44430, México; \\ eroxanita@gmail.com \\ *E-mail: edgar.mmedrano@academicos.udg.mx
}

doi: $10.20964 / 2020.01 .14$

Received: 15 August 2019 / Accepted: 18 October 2019 / Published: 30 November 2019

This work is focused on understanding the interaction of native galena minerals and xanthate as well as their influence on the process of mineral separation by flotation and leaching techniques. To obtain basic and fundamental information about this interaction, a quantitative analysis of an electrochemical impedance study based on a mechanistic approach and the obtaining of its impedance transfer function is presented. The impedance transfer function was obtained from a three-reversible-stage mechanism, which included 19 parameters, all of which were satisfactorily obtained by fitting the impedance transfer function to previously reported experimental impedance spectra of the galena/xanthate interface in a wide polarization potential range of -0.2 to $0.5 \mathrm{~V}$ vs. SCE. The fitting procedure consisted of the application of a differential evolution (DE) algorithm. The description of this algorithm, its application and its advantages in the electrochemical impedance field are presented. Furthermore, a detailed discussion about the quantitative values obtained and its interpretation for galena/xanthate interactions is presented.

Keywords: galena, xanthate, impedance, adsorption mechanics, differential evolution algorithm.

\section{$\underline{\text { FULL TEXT }}$}


(C) 2020 The Authors. Published by ESG (www.electrochemsci.org). This article is an open access article distributed under the terms and conditions of the Creative Commons Attribution license (http://creativecommons.org/licenses/by/4.0/). 